\title{
Bacterial cellulose nanofiber reinforced poly (lactic acid) nanocomposite
}

\begin{abstract}
The objective of the present work is to investigate the impact of the modified $\mathrm{BC}$ nanofibers orientation in poly (lactic acid) (PLA)/polyethylene glycol (PEG) blends (porous and nonporous) on the mechanical properties and thermal properties. A new class of PLA/PEG biocomposites containing BC nanofibers was successfully fabricated using solution casting technique followed by silane coupling agent of $\mathrm{BC}$ grafting into PLA/PEG chains. The mechanical properties were investigated with and without developing the porosity for PLA/PEG. The results revealed that incorporating $\mathrm{BC}$ nanofibers into PLA/PEG enhanced mechanical properties, but this improvement set up at $\mathrm{BC}$ nanofiber loading ( $5 \mathrm{wt} \%)$. The tensile strength increased from $13 \mathrm{MPa}$ for PLA/PEG to $18 \mathrm{MPa}$ after the addition of $5 \mathrm{wt} \% \mathrm{BC}$. The young's modulus was significantly increased upon increased BC content. Differential Scanning Calorimetric (DSC) results revealed that the $\mathrm{BC} 5 \%$ nanofiber improved glass transition temperature $\left(\mathrm{T}_{\mathrm{g}}\right)$ to $57^{\circ} \mathrm{C}$, melting temperature $\left(\mathrm{T}_{\mathrm{m}}\right)$ to $171^{\circ} \mathrm{C}$, and crystallinity $(\chi \%)$ to $43 \%$ of PLA/ PEG reinforced-BC-5\%. These results are of significant interest to further expand the use of PLA in biomedical applications..
\end{abstract}

Keywords: poly (lactic acid), bacterial cellulose nanofibers, polyethylene glycol, nanocomposites
Volume I Issue 5 - 2017

\author{
Mustafa Abu Ghalia, Yaser Dahman \\ Department of Chemical Engineering, Ryerson University, \\ Canada
}

\author{
Correspondence: Yaser Dahman, Department of Chemica \\ Engineering, Ryerson University, 350 Victoria St., Toronto, \\ Ontario M5B 2K3, Canada, Tel 416-979-5000, Fax 416-979-5083, \\ Email mabughal@ryerson.ca
}

Received: October 23, 2017 | Published: November 27, 2017
Abbreviations: PLA, poly(lactic acid); PEG, polyethylene glycol; DSC, differential scanning calorimetric; $\mathrm{T}_{\mathrm{m}}$, melting temperature; $\mathrm{T}_{\mathrm{g}}$, glass transition temperature; VST, vicat soft temperature; $\mathrm{BC}$, biocellulose

\section{Introduction}

Recent developments in the synthetic degradable polymers have been the subject of significant interest for macromolecular science to both of an environmental and biomedical perspective with dedication towards applications in tissue engineering and drug delivery. The best candidate for degradable polymer is poly (lactic acid) (PLA), which is described as aliphatic polyester. ${ }^{1}$ It is produced from renewable resources of agriculture via combined fermentation and polymerization processes. Considering that PLA has several remarkable properties, such as relatively high modulus and hardness at ambient temperature, it is a candidate as a replacement for traditional petroleum based polymers. In contrast, the PLA application is still restricted because of the low glass transition temperatures $\left(\mathrm{T}_{\mathrm{g}}\right)$, vicat soft temperature (VST), and frailty. ${ }^{2,3}$ The blending of binary degradable polymers and copolymerization can enhance the limitation of mechanical properties. ${ }^{4}$ However, immiscibility and non-compatibility are considerable barriers in developing PLA with superior properties. ${ }^{5}$

Biocellulose (BC) nanofibers are potentially considered as one of the utilizing natural resources to employing into the degradable polymer. Lately, several scientists are attracted to the $\mathrm{BC}$ nanofibers, due to the superiority in biocompatibility and mechanical properties. $\mathrm{BC}$ can be prepared from fermentation process throughout a specific type of bacterial strains. The unique structure of $\mathrm{BC}$ is formed from the pure form of cellulose nanofibers, which contains a high degree of crystallinity associated with a high degree of polymerization. ${ }^{6}$ These exceptional properties also possess potential forerunner for development technologies in the various significant area, such as tissue engineering, sustainable polymeric biomaterials, and green nanocomposites. ${ }^{7}$ BC nanofiber reinforced into PLA nanocomposite has gained much consideration because of their low density, inexpensive, non-abrasiveness; very low toxicity and degradable properties. Several reports ${ }^{6-8}$ revealed that the mechanical and thermal properties of degradable polymers are enhanced when using an appropriate Compatibilizer with the cellulose nanofibers. The non-uniform dispersion can cause inferior tensile strength and highwater absorption. Hence, the suitable interface Compatibilizer agent between the PLA matrices and BC nanofibers would lead to improving $\mathrm{BC}$ distribution. Meanwhile, $\mathrm{BC}$ contents reduced surface polarity when interacting with PLA and improved reinforced efficiency. ${ }^{9,10}$

In recent years, surface modification of (BC) by grafting coupling agent into PLA matrices has demonstrated a special interest in reducing the number of hydroxyl groups and enhance the surface hydrophobicity of BC nanofibers. ${ }^{11}$ Silane chains can enhance interaction between PLA matrices and BC nanofibers. ${ }^{12}$ Moreover, the presence of polyethylene glycol (PEG) in PLA blends lead to improving hydrophilicity and accelerates its degradation rate. Various silanes are potentially considered as effective agents in enhancing the interface between PLA/PEG blends and BC nanofibers. This involves the alkoxysilanes creating bonds with $\mathrm{BC}$ hydroxyl function groups. Additionally, the organ functional group is spontaneously reacting with PLA through covalent bonding. ${ }^{13}$

\section{Preparation of the PLA/PEG copolymer-BC nano- composites}

The PLA/PEG was prepared in a reaction vessel equipped with an overhead stirring shaft. The copolymer and $\mathrm{BC}$ were heated at $60^{\circ} \mathrm{C}$ for $2 \mathrm{~h}$ until the relative vapor content was less than $1.0 \mathrm{wt} \%$. Afterward, the PLA/PEG heated for about half an hour at $110^{\circ} \mathrm{C}$, ensuring all PLA/PEG convert to the high viscous solution, and later on the $\mathrm{BC}$ suspension solution was mixed with a presence of dicumyl peroxide for $15 \mathrm{~min}$ at $170^{\circ} \mathrm{C}$ and rotation speed $60 \mathrm{rpm}$. The 
peroxide produced a free radical on the $\mathrm{BC}$ surface to further reacted with hydrogen group of copolymer. The $\mathrm{BC}$ nanofiber amounts were $1 \mathrm{wt} \%, 2.5 \mathrm{wt} \%$, $5 \mathrm{wt} \%$, and $10 \mathrm{wt} \%$. The $\mathrm{BC}$ treated coupling agent was grafted onto the PLA/PEG side chains and therefore form BCreinforced PLA/PEG as illustrated in the reaction (Figure 1). All the samples were poured using tensile prototype molding ( $2 \mathrm{~mm}$ thick) at $110^{\circ} \mathrm{C}$ and subsequently kept for $24 \mathrm{~h}$ at ambient temperature under vacuum to eliminate the solvent and allow the copolymer chains to reconstruct.

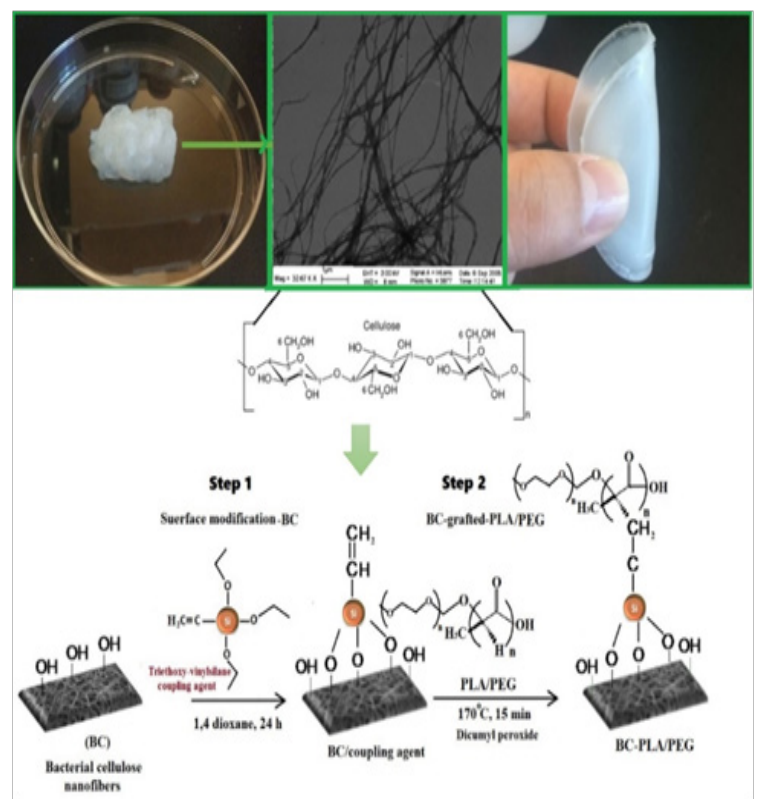

Figure I The reaction between coupling agent and BC, (step I), BC grafted PLA/PEG copolymer (step 2).

\section{Results \& discussion}

The addition of $\mathrm{BC}$ content in PLA/PEG demonstrated a different trend in tensile strength properties. It is clearly seen from Figure 2(A) that the tensile strength of the PLA/PEG was enhanced as a function of increased $\mathrm{BC}$ loading up to $5 \mathrm{wt} \%$ and a drastic decrease with the addition of $\mathrm{BC}-10 \mathrm{wt} \%$. In the meantime, the young's modulus of
PLA/PEG reinforced-BC\% and PLA/PEG-scaffold-BC\% increased with an addition of $\mathrm{BC}$ content as represented in Figure 2 (B). The compressive strength obtained for PLA/BC-5wt $\%$ was $9.8 \mathrm{MPa}$, which significantly dropped after $\mathrm{BC}-10 \mathrm{wt} \%$ to $8.8 \mathrm{MPa}$ (Figure $2(\mathrm{C})$ ).

It is noted that both the $\mathrm{T}_{\mathrm{g}}$ and $\mathrm{T}_{\mathrm{m}}$ in Table 1 are slightly increased relative with the increased $\mathrm{BC}$ nanofibers. PLA/PEG contains $\mathrm{T}$, $\mathrm{T}_{\mathrm{c}}$, and $\mathrm{T}_{\mathrm{m}}$ of 53,121 , and $168^{\circ} \mathrm{C}$ respectively. The $\mathrm{T}_{\mathrm{g}}$ of PLA/PEG scaffold without $\mathrm{BC}$ stayed at approximately $51^{\circ} \mathrm{C}$, which indicates that weak interfacial bonds among the copolymers. An increase in the degree of crystallinity $43 \%$ of PLA/PEG blends with an addition of $\mathrm{BC}-5 \%$ attributed to the fact that the PEG acts as plasticizers in the PLA matrices. As well as, the addition of BC\% constricting PLA/ PEG chain movements. In addition, both the $\Delta \mathrm{H}_{c}$ and $\mathrm{T}_{\mathrm{c}}$ decrease with increased $\mathrm{BC}$ nanofiber. This indicates that $\mathrm{BC}$ is acting as a nucleating agent, and promoting crystallization in the PLA/PEG copolymer. ${ }^{12,13}$
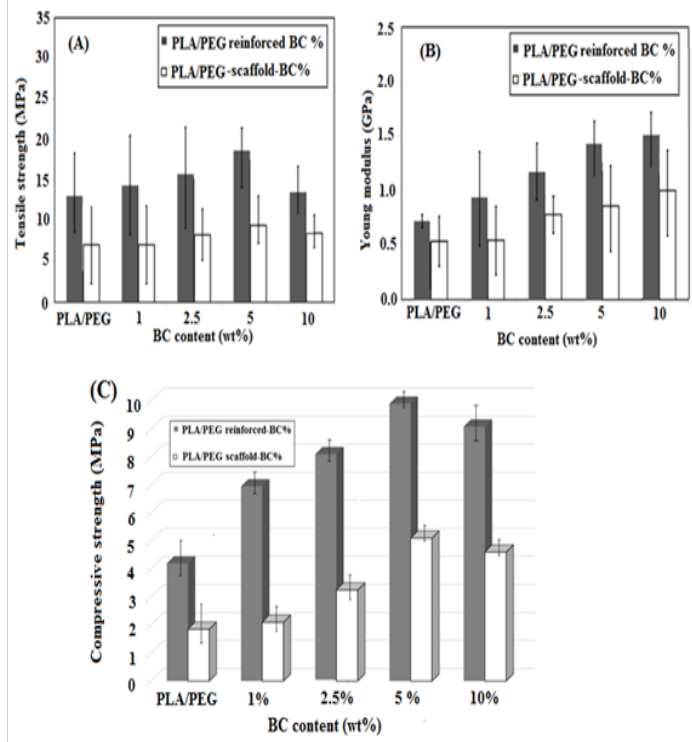

Figure 2 The effect of $B C$ content on the tensile strength $(A)$ and young modulus (B) of PLA/PEG-BC with and without porous scaffold, (C) the effect of $B C$ contents on the PLA/PEG compressive strength.

Table I Thermal stability of PLA/PEG with and without porous scaffolds incorporated with varying of (BC I-I0wt\%)

\begin{tabular}{llllllll}
\hline Code & Samples & $\mathbf{T}_{\mathbf{g}}\left({ }^{\circ} \mathbf{C}\right)$ & $\mathbf{T}_{\mathbf{c}}\left({ }^{\circ} \mathbf{C}\right)$ & $\mathbf{T}_{\mathbf{m}}\left({ }^{\circ} \mathbf{C}\right)$ & $\Delta \mathbf{H}_{\mathrm{c}}(\mathbf{J} / \mathbf{g})$ & $\Delta \mathbf{H}_{\mathbf{m}}(\mathbf{J} / \mathbf{g})$ & $\chi \%$ \\
\hline A & PLA/PEG & 53 & 121 & 168 & 14.3 & 9.3 & 33 \\
B & PLA/PEG reinforced-BC 1\% & 54 & 119 & 168 & 13.7 & 12.5 & 35 \\
C & PLA/PEG reinforced-BC 2.5\% & 54 & 119 & 169 & 12.6 & 15.1 & 37 \\
D & PLA/PEG reinforced-BC 5\% & 57 & 116 & 171 & 12.9 & 25.8 & 43 \\
E & PLA/PEG reinforced-BC 10\% & 55 & 115 & 158 & 11.5 & 19.7 & 35 \\
F & PLA/PEG scaffold & 51 & 118 & 162 & 10.4 & 4.6 & 24 \\
G & PLA/PEG scaffold -BC 1\% & 45 & 113 & 157 & 8.6 & 8.1 & 26 \\
H & PLA/PEG scaffold-BC 2.5\% & 47 & 110 & 156 & 7.2 & 8.7 & 28 \\
I & PLA/PEG scaffold-BC 5\% & 48 & 91 & 156 & 6.8 & 10.8 & 29 \\
J & PLA/PEG scaffold-BC 10\% & 43 & 87 & 154 & 5.7 & 7.2 & 22 \\
\hline
\end{tabular}




\section{Conclusion}

A new class of polylactic acid (PLA)/polyethylene glycol (PEG) copolymer reinforced with bacterial cellulose nanofibers (BC) was prepared using a solvent casting and particulate leaching methods. The results of mechanical and thermal properties demonstrated that the PLA/PEG synthesized is good candidate for developing scaffolds for three-dimensional porous structures, which can be implemented into various tissue engineering applications such as surgical sutures, and drug delivery devices.

\section{Acknowledgements}

None.

\section{Conflicts of interest}

The author declares no conflict of interest.

\section{References}

1. Fergal J Obrien. Biomaterials \& scaffolds for tissue engineering. Mat-Tod. 2011;14(3):88-95.

2. Goonoo N, Bhaw-Luximon A, Bowlin GL, et al. An assessment of biopolymer-and synthetic polymer-based scaffolds for bone and vascular tissue engineering. Polym Int. 2013;62(4):523-533.

3. Abu Ghalia M, Yaser D. Investigating the effect of multi-functional chain extenders on PLA/PEG copolymer properties. International journal of Biological Macromolecules. 2017;95:494-504.

4. Zhu X, Zhong T, Huang R, et al. Preparation of hydrophilic poly (lactic acid) tissue engineering scaffold via (PLA)-(PLA-b-PEG)-(PEG) solution casting and thermal-induced surface structural transformation. $J$ Biomat Sci Polym Ed. 2015;26(17):1286-1296.
5. Wahib A, Yaser D. Production of green biocellulose nanofibers by Gluconacetobacter xylinus through utilizing the renewable resources of agriculture residues. Bioprocess Biosyst Eng. 2013;36(11):1735-1743.

6. Dahman Y, Jayasuriya KE, Kalis M. Potential of biocellulose nanofibers production from agricultural renewable resources: preliminary study. Appl Biochem Biotechnol. 2010;162(6):1647-1659.

7. Kalia S, Kaith, BS Kaur I. Pretreatment of natural fibers and their application as reinforcing material in polymer composites-a review. Polym Eng Sci. 2009;49(7):1253-1272.

8. Avérous F, Le Digabel F. Properties of biocomposites based on lignocelluosic fillers. Carb Polym. 2006;66(4):480-493.

9. Keledi G, Sudár A, Burgstaller Ch. Tensile and impact properties of three-component/wood/elastomer composites. Express Polym Lett. 2012;6(3):224-236.

10. Thomason JL, Vlug MA. Influence of fibre length and concentration on the properties of glass fibre-reinforced polypropylene: 4. Impact properties. Compos Part A: Applied Science and Manufacturing. 1997;28(3):277-288.

11. Abu Ghalia M, Yaser D. Fabrication and enhanced mechanical properties of porous PLA/PEG copolymer reinforced with bacterial cellulose nanofibers for soft tissue engineering applications. Polym Testing. 2017;61:114-131.

12. Najafi N, Heuzey MC, Carreau PJ. Polylactide (PLA)-clay nanocomposites prepared by melt compounding in the presence of a chain extender. Compos Sci Technol. 2012;72(5):608-615.

13. Jonoobi M, Mathew AP, Abdi MM, et al. comparison of modified and unmodified cellulose nanofiber reinforced polylactic acid (PLA) prepared by twin screw extrusion. J Polym Environ. 2012;20(4):991-997. 